\title{
HOME AUTOMATION USING ZIGBEE TECHNOLOGY AND IOT
}

\author{
Dr Syeda Gauhar Fatima \\ Professor ECE dept, Deccan College of Engineering and Technology \\ Darussalam, Hyderabad, India \\ Syeda Kausar Fatima
}

Associate Professor, Shadan College of Engineering and Technology, Hyderabad, India

\section{Dr Syed Abdul Sattar}

Principal, Nawab Shah Alam College of Engineering and Technology,

New Malakpet, Hyderabad, India

Syed Adil

Student, ECE dept, Deccan College of Engineering and Technology,

Darussalam, Hyderabad, India

Khaja Fouzan Ahmed

Student, ECE dept, Deccan College of Engineering and Technology,

Darussalam, Hyderabad, India

\begin{abstract}
ABTRACT
Technology is a never ending process. From the past decade has seen significant advancement in the field of consumer electronics. Various devices such as cellular phones, air conditioners, home security devices, home theatres, etc. are lead us to smart home/home automation. They have given rise to a PAN (Personal Area Network) in home environment, where all these appliances can be interrelated and monitored using a single controller. Busy personalities and physical limitation/old aged people require home automation and networking to ease their work. Home automation networks uses many systems like wireless embedded sensors and actuators that allows monitoring and control applications for home user and give an efficient home management.
\end{abstract}

Keywords: PAN, Controller, Wireless embedded sensors, Actuators.

Cite this Article: Dr Syeda Gauhar Fatima, Syeda Kausar Fatima, Dr Syed Abdul Sattar, Syed Adil and Khaja Fouzan Ahmed, Home Automation Using Zigbee Technology and IOT, International Journal of Advanced Research in Engineering and Technology, 10(2), 2019, pp. 92-96.

http://iaeme.com/Home/issue/IJARET?Volume=10\&Issue $=2$ 


\section{INTRODUCTION}

In recent years, wireless sensor and actuator networks have enlarged momentum, receiving momentous attention from academia, industry, and standards development organizations. One of the chief application domains of this technology is home automation. This system enables us to access monitoring and control applications for the home user and effective home management a WHAN (Wireless Home Automation network) characteristically comprises several types of strictly constrained embedded devices, which may be battery powered and are furnished with low-power Radio Frequency (RF) transceivers. The use of RF communication allows flexible addition or removal of devices to or from the network and reduces installation costs since wired solutions require channels or cable trays. However, the dynamics of radio propagation, resource drawbacks, and the mobility of some devices challenge the design of WHANs. We then present an overview of ZigBee, ZWave, INSTEON, Wavenis, and IP-based approaches. We then discuss these solutions with regard to WHAN requirements plus additional technical and nontechnical criteria.

\section{EXISTING SYSTEM ISSUES}

- Problems with integration

- Electrical issues

- Physical damage

- Your home network

- System designed for budget rather than performance

- Energy efficiency

- Extensibility

\section{PROPOSED SYSTEM}

\subsection{Light control}

A new light can be controlled from any switch, which reduces the need for new wired connections. Lights can also be activated in answer to a command from a remote control. Furthermore, they can be turned on automatically when presence and luminance sensors detect that people are in an off-color illuminated room.

\subsection{Remote control}

Infrared technology has been used for wireless communication between a remote control and devices such as TVs, HiFi equipment, and heating, ventilating, and air conditioning (HVAC) systems. However, infrared requires line-of-sight (LOS) and short-distance communication. RF technology overcomes these drawbacks. Intercommunication between the appliances inside the home.

\subsection{Smart energy}

We use Window shades to rotatable according to sunshine, HVAC, central heating, and so on may be controlled subject to the information collected by many types of sensors that are used to monitor parameters around the home such as Motion, light, humidity, thermostat etc.. In addition, smart utility meters can be used to sense usage peaks and alert the household devices that may be causing them. Energy supply firms may also use WHANs to perform energy load management. 


\subsection{Security and safety}

Advanced security systems can be based on several sensors (e.g., smoke detectors, glass-break sensors, and motion sensors) for detecting possible risk situations that trigger appropriate actions in response. For example, smoke detectors may activate fire alarm. The proposed system employs the biometric in the authentication for home entrance which enhances home security as well as lenience of home entering process which can be overruled by OTP sent to mail and phone for giving authorization to relatives and others.

\subsection{Voice recognition}

The voice recognition system uses a single-chip solution for recognizing the voice. LD3320 is a chip which is used to recognize the voice based on speaker-

\section{SYSTEM ARCHITECTURE}

Liberated automatic voice recognition technology. LD3320 has an extremely operative speakerindependent voice recognizer. It is designed with hardware optimization and acceleration for speech recognition, without any external supporting devices such as Flash, RAM, etc. It can complete speech recognition at a precision rate of $95 \%$, not even requiring users to do their own voice training to create speech features for the training library. So the cost of voice recognition module is inferior to SUNPLUS SPCE061A. It first examines the spectrum of the voice input by the MIC and then extracts the voice features. After that, it's compared with words in the list of keywords. Finally, the keyword with the highest score is output as the recognition result.

\subsection{Remote care}

Patients and disabled and elderly citizens can benefit from at home medical attention. Wearable wireless sensors can occasionally report the levels of several body parameters (e.g., temperature, blood pressure, and insulin) for an exact diagnosis. If acceleration sensors recommend that a person has fallen, alarms can be activated instantly and smart air control to maintain the fresh air inside the home by means of a geothermal pump and smart ventilation by allowing mandatory amount of sunlight into the home.

\subsection{Features of the proposed system}

- Increase the lifespan of each appliance in the home

- Very appliance act as they can receive the commands so therefore it doesn't have to wait for any future permissions

\section{SYSTEM DESCRIPTION}

An actuator is a device which is liable for moving and controlling a system, an actuator requires a control signal which requires very low energy that can be generated by means of hydraulic pressure and current to control the system. When it receives a control signal it retorts to System by converting the signals into mechanical motion.

An audio power amplifier an electronic device that is used to generate audio signals and increase its level to strong that is good enough for voice reform and home audio system. 


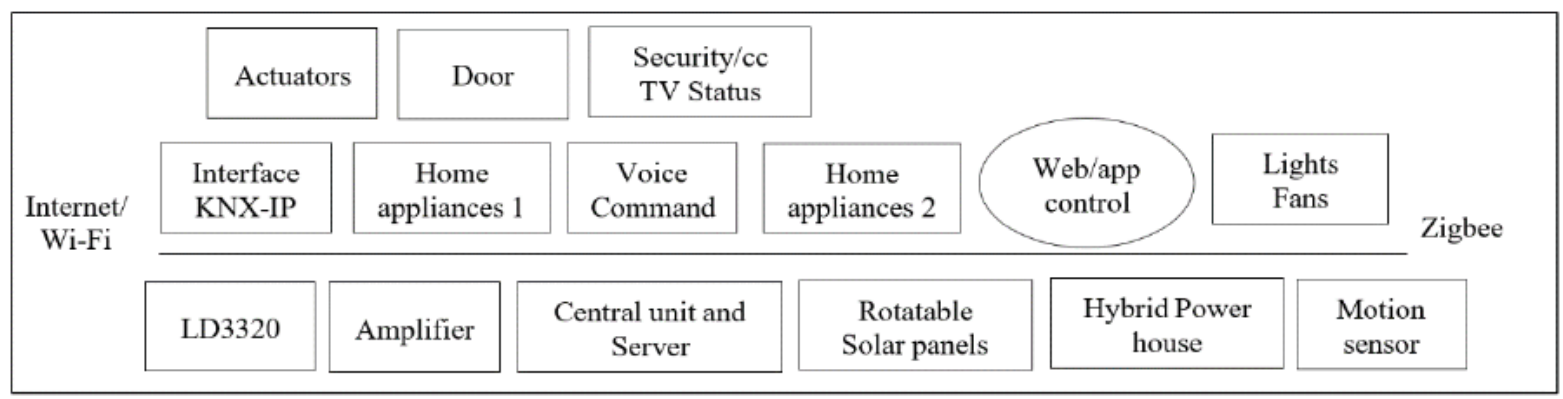

Figure 1 System architecture

A Central Unit \& Server has the commands information and how to perform the task and to whom the task is allocated sends the signal to particular device and device performs the action consequently it stores the past commands given to it by the user in the cloud.

An LD3320 is used to receive the commands via voice and transmits the information to the central unit from their process proceeds to action. We can also interconnect with any of the devices that are connected and allocate the task through voice commands.

WEB/APP we can also control the home by the website or by the app. We can allot the task by home. With this help, we can control the home from any part of the world.

Motion Sensor: This Sensor used to detect the motion and turn on/off the device accordingly like lights and fans.

Rotatable Solar Panels: This is new to everyone that this solar panel rotates according to the sunlight to make the maximum angle of inclination with the sun and make maximum energy.

Hybrid Power House: This stores the power that generated by the solar panels and distributes to the devices that are in the home the entire home runs on power generates by solar panels if the powerhouse is having $1000 \mathrm{kWh}$ then it switches to EB

Zigbee is an IEEE 802.15.1 based is used for high-level communication protocols used to creates PAN Which requires low-power and these are used in digital radio and used for data collection, and it has low data rate and more cost-effective as it has low power consumption its distance is limited.

\section{CONCLUSION}

This paper has shown the issues with current system state of home automation systems and a home automation system is projected using the latest communication technology ZigBee.The use of ZigBee communications technology which is less expensive and operative and This leads to the concept of the virtual home which has security and safety efforts in a clear and reliable manner The home gateway in this type of implementation provides interoperability between the local ZigBee, Wi-Fi, and the Internet. The System offers a various type of networks and devices used to access the system. Proposed system architecture has the benefits of low cost, flexible and reliable and secure system the developed system has generous support for the various devices and modes of control, monitoring, and feedback of home.

\section{REFERENCES}

[1] ZigBee Alliance, "ZigBee Smart Energy Profile Specification,” revision 15, Dec. 2008

[2] A. ElShafee and K. Alaa Hamed, "Design and Implementation of a WiFi Based Home Automation System," World Academy of Science, Engineering and Technology, 2012

[3] Sarang D. Patil and Prof. S.N. Pawar, Wireless AMR System Using Zigbee Technology, International Journal of Electronics and Communication Engineering \& Technology (IJECET), Volume 3, Issue 2, July-September (2012), pp. 107-115 
[4] C. Gomez and J. Paradells, "Wireless Home Automation Networks:A Survey of Architectures and Technologies," IEEE Communications Magazine, 2010.

[5] K. Raghava Rao, Monika Vallabhaneni, Srikanth Narayanaraju, Rajendra Kumar Jonnalagadda and Sunilkumar kanaparthi, Air Pollution Monitoring Using Zigbee Based Wireless Sensor Networks, International Journal of Electronics and Communication Engineering \& Technology (IJECET), Volume 5, Issue 5, May (2014), pp. 56-63

[6] Miss. Smita B. Garde and Prof. S. L. Kotgire, Coalmine Safety System with Zigbee Specification, International Journal of Electronics and Communication Engineering \& Technology (IJECET), Volume 4, Issue 2, March - April, 2013, pp. 504-512

[7] N. Sriskanthan and Tan Karand. "Bluetooth Based Home Appliance", The $9^{\text {th }}$ International Conference on Advanced Automation System". Journal of Microprocessors and Communication Technology, pp.1583-1586, 2007

[8] Kedar S.F, Abdullah, Sudhindra F, Annarao S.J, Vani R.M and B.S Motgi, Development of Zigbee Based Tele Operated Multipurpose Robotic Arm with Hand Gesture Recognition, International Journal of Mechanical Engineering and Technology 8(8), 2017, pp. 12751286

[9] Sanket Gupta, G. Rohith, CH Amul and K. Vadivukkarasi, Electronic Toll Collection System Using Zigbee and RFID. International Journal of Civil Engineering and Technology, 8(4), 2017, pp. 1714-1719

[10] D. Yoon, D. Bae, H. Ko and H. Kim, "Implementation of Secure PIC Based Remote Control Application for Home Gateway and GUI for Control the Home Intelligent Home". International Journal of Computer Science and Network Security, Vol. 7, No. 5, May 2007

[11] Ansari Md. Asif Md Riyasat, MsVijayshree A More, Prof. J. G. Rana and Dr. S. A. Naveed, Green House Monitoring Based on Zigbee, International Journal of Computer Engineering and Technology (IJCET), Volume 3, Issue 3, October - December (2012), pp. 147-154. 